\title{
Multidisciplinarity in economics education and how it can shape economic thinking in the future
}

\author{
Adrian - Ioan DAMOC \\ The Bucharest University of Economic Studies, Bucharest, Romania \\ adrian_ioan_damoc@yahoo.com
}

\begin{abstract}
During the period known as the economic and global financial crisis, economic forecasting came under heavy criticism for its inability to predict the crisis, to the point where said crisis was deemed not just a crisis of the global economy, but of economic thinking as well, in particular mainstream, neoclassical economics. The critique of economics has focused primarily on the following aspects: its unrealistic assumptions regarding markets and human behaviours; its poor track record in predicting phenomena such as the crisis itself; its over-reliance on models that bear little resemblance to real world conditions, and also that it has a very narrow focus, reluctant to integrate useful inputs from other fields, which is perceived as leading to stagnation and hindering progress in the field. Following the crisis, several academic debates occurred within the field of economics, with several heterodox schools of economic thought receiving renewed attention, while universities have begun to expand the range of disciplines included in their business programmes, gravitating towards a multidisciplinary approach. The present paper aims to examine the concept of multidisciplinarity with a focus on its role in business education today and to assess the extent to which its spread and prevalence can usher in a new paradigm in economic thinking.
\end{abstract}

Keywords: multidisciplinarity, transdisciplinarity, interdisciplinarity, paradigm, education, crisis, heterodox

\section{Introduction}

The global financial crisis of 2007-2008 began in the United States and spread throughout the global economy, giving way to the economic decline known as the Great Recession, arguably the most severe recession since the Great Depression, according to the Encyclopaedia Britannica (https://www.britannica.com/list/5-of-the-worlds-mostdevastating-financial-crises). The crisis took the world by surprise not only with its reach, scope and effects, but also because it eluded most economic forecasts that had been made in its prelude; former US Federal Reserve Chairman Alan Greenspan called it "an existential crisis for economic forecasting" and believed that conventional prediction methods failed when they were required most (Greenspan, 2013). Mathematician David Orrell (2017) compares the confidence that economics enjoyed prior to the crisis and the criticism it received in its aftermath, stressing that the models used had proven highly unrealistic and failed to capture essential aspects of the economy, an opinion that is also shared by economist Paul Romer (2016). This situation amplifies with the emergence of the knowledge economy and understanding the concepts of knowledge and knowledge dynamics (Bratianu, 2011a, 2011b, 2013).

These core critiques were levelled against economics even before the crisis emerged. For instance, Philip Mirowski (2002) once characterised the field of economics as becoming more and more similar to what he termed a 'cyborg science' and argued that economists have done themselves a disservice by resisting the influence of postmodern currents. In the 
context of the crisis, the critical voices gained more strength. Criticism was also directed to certain biases perceived to be inherent in the economic profession, such as a free-market bias, along with using outdated tools and concepts that proved unable to accurately pick up on the signs of the crisis as they emerged. Some economists such as Wharton professor Franklin Allen (cited in Wharton School, 2009) even asserted that the economists that did understand that a crisis would unfold chose to disregard the possibility, insofar as it did not fit the theory. Another member of Wharton's faculty, Sidney G. Winter (cited in Wharton School, 2009) posited that owing to this overreliance on mathematical models, many important factors that govern human interaction - including economic phenomena - were discarded; among these, he cites human psychology and cognitive biases that influence the behaviour of economic agents. The economists that did identify the early signs of the housing bubble that underlay the crisis failed nonetheless to fully comprehend its consequences, as per the opinion of Wharton international banking professor Richard Herring (cited in Wharton School, 2009).

Colander et al. (2009) concurred that the failure of the economics profession to identify the characteristics of the crisis in its nascence was due to misguided research, with an insistence upon constructing models to the detriment of understanding the key elements that govern market behaviours in the real world. Furthermore, they assert that in the academic community, the limitations of the powers of these models were not properly acknowledged and, in line with the other sources cited heretofore, that these models were based upon unrealistic expectations regarding economic agents and failed to properly capture the heterogeneity that exists among them. An author for the Financial Times (2014) points to the existence of a body of research in heterodox economics that dealt with the exact issues that led to the crisis, but judges it against the overly abstract nature of a discipline that seeks to deal with real world phenomena.

Against the backdrop of these criticisms, the academic community saw renewed interests towards heterodox view of economics, such as Austrian economics and behavioural economics, with Richard Thaler earning the Nobel Memorial Prize in Economic Sciences for his contributions to the latter field. Another shift, on which the present paper focuses, takes place at the level of economics education. Pressure on universities to reform their curricula began to increase as students clamoured for including alternative views in the programmes. One such movement was a student movement at the University of Manchester that coalesced into the "Post-Crash Economics Society", which promotes reform of economic curricula in universities in the hopes of bringing about progress in the field by encouraging pluralism in economic thinking (Inman, 2013). It was followed in 2014 by the International Student Initiative for Pluralist Economics, a coalition of student groups that similarly endorse pluralism in economics. The idea of pluralism in economics - that is, a better representation of several schools of economic thought in academia - is not new, however, as its origins can be traced back to the 1960s. A related movement is the postautistic economics movement, originating in France, with the term "autistic" being employed with the older meaning in French of "excessive subjectivity". The movement was born in the year 2000, its tenets being exposed in an open letter published in Le Monde (2000). 
Pluralism is also encouraged by Dutt (2010), which in the author's opinion should extend to several levels: methodologies, ideologies and policies. In short, after the crisis, a lot of pressure began to accumulate in favour of a reform in how economics is taught. Several universities in the UK have since begun to implement changes in their economics curricular frameworks, such as the Curriculum in Open-access Resources in Economics (CORE) programme launched by Oxford University, seeking to tackle a range of issues in the hopes of expanding the horizons of economics in education. In spite of this, Mearman et al. (2016) criticised the programme for its limited pluralism and adherence to the mainstream views. On the other hand, they contrast this system with the Brazilian approach, favouring the latter as "more pluralist, liberal and progressive" with a "commitment to realism and pluralism" (Mearman et al., 2016: 16-17).

The pattern that we need to discern here, therefore, is that after the global financial crisis of 2008, increasing criticism against the mainstream paradigm in economics has been linked to an increase pressure upon the academia to produce change in how economics is currently taught. While the previous paragraphs have dealt with pluralism, the focus of the present paper is on a wider trend - namely that towards multidisciplinarity.

\section{Methodology, structure and hypotheses}

The hypotheses that we seek to analyse are: 1) That multidisciplinarity is an increasing trend in education and that economics is not an exception to it, and 2) That multidisciplinarity should gradually determine a shift in the research output in economics as new avenues become available.

The paper is structured into the following main sections: 1) A distinction between multidisciplinarity and the related concepts of transdisciplinarity and interdisciplinarity for greater clarity; 2) An overview of the current prevalence of multidisciplinarity in education in general and in economics in particular; 3) An examination of the extent to which a multidisciplinary approach can effect a change in the dominant paradigm of economic thought; 4) Conclusions based on the previous points.

The methodology employed in this paper is the following: 1) A review of the existing literature on multidisciplinarity and its conceptual identity among other forms of collaboration between various fields of knowledge, and 2) Inductive and deductive methods to pinpoint the underlying patterns and discern its potential consequences for the development of economics.

\section{Conceptual clarification of multidisciplinarity, transdisciplinarity and interdisciplinarity}

Although all three terms share the same root and involve holistic approaches by incorporating insights from several disciplines, the concepts of multidisciplinarity, transdisciplinarity and interdisciplinarity are not interchangeable and as such, we need to pinpoint the key differences between them. One such distinction is made by Choi \& Pak (2006). They offer the following definitions: multidisciplinarity as pooling knowledge from various disciplines, with each retaining their individual identities; interdisciplinarity involves holistically synthesising different links between disciplines into something new; 
transdisciplinarity dissolves the boundaries between disciplines regardless of their domain (natural, health or social) and brings them together. Alexander Refsum Jensenius (2012) sees the three as different steps of a five stage process of integration between disciplines, beginning with intradisciplinarity (i.e. operating within one's own narrow field) and ending in transdisciplinarity (the creation of a unique framework that disregards the boundaries of the fields of origin).

PICBE | 266

Marilyn Stember (1991) targeted the roles of these notions in the realm of the social sciences specifically, focusing on interdisciplinarity in particular. She acknowledges the ambiguity of the terms, with broad and narrow senses existing in the literature which often lead to interdisciplinarity and multidisciplinarity being used interchangeably. To clarify matters, Stember (1991: 4) offers the following definitions: intradisciplinarity as operating within the scope of a single field; crossdisciplinarity as adopting perspectives from other disciplines to tackle a certain discipline; multidisciplinarity is defined as several disciplines providing different insights on a problem, leading to the integration of diverse ideas; interdisciplinarity refers to the integration of several disciplines as a prerequisite for solving a given problem; finally, transdisciplinarity is seen as building a unitary intellectual framework surpassing the boundaries of the original disciplines. Nevertheless, Stember points out that there is overlapping among these various types of interactions between disciplines.

Another, more restrictive perspective on the definition and distinction between multi-, inter- and transdisciplinarity is given by Goschin and Zaman (2010). They view multidisciplinarity as the aggregation of several disciplines without any fundamental change to their points of view, with the emergent relationships between them being of cumulative rather than interactive nature, aiming to create a more complex and nuanced picture. Interdisciplinarity, on the other hand, requires the combination of techniques, hypotheses and methodologies specific to various disciplines in order to arrive at a common objective, according to the demands of the research project at hand. Meanwhile, transdisciplinarity is characterised by its holistic tendencies, aiming at creating broader knowledge beyond its parent disciplines. One key difference they note between multi- and interdisciplinarity is that the latter generates new methods and hypotheses better suited to the project being researched, whereas the former does not. They also stress that these three categories of combining disciplines are not contradictory, but complementary.

Dawn Youngblood's definitions (2007) do not deviate much from the previously presented points of view. In her opinion, multidisciplinarity also involves the cooperation of at least two fields of knowledge in order to bring about a more nuanced understanding of a given problem, where "tools and expertise from one discipline are applied to another". Interdisciplinarity is seen through the lens of its integrative nature that gives way to the creation of new methods and theories irrespective of the limits of the disciplines they were derived from, thus this view tends to overlap with the previous authors' definition of transdisciplinarity. She argues that unlike multidisciplinarity which focuses on the domain, interdisciplinarity focuses on the process. An interesting aspect that she underscores is that interdisciplinarity would require a strong basis in multidisciplinarity.

For the purposes of this paper, by multidisciplinarity we shall understand the integration of ideas, concepts, analytical tools and methodologies from various fields into 
the scope of one field, in order to enrich theory and gain a better, multilayered understanding of the phenomena being researched. In particular, we examine what multidisciplinarity means for economics and how it can aid in developing economic theory.

\section{Multidisciplinarity in education and research}

While Vastag (2008) notes that the concept of multidisciplinarity has been discussed in the academic world for about two decades, the application of the multidisciplinary approach is uneven over time and across the various academic fields. For example, Schummer (2004) noted that in nanoscience and nanotechnology research, at the time of his research, there was no particular pattern towards interdisciplinarity or multidisciplinarity, despite substantial efforts being made in that direction; he also points out that there were "strong cognitive barriers to interdisciplinary collaboration in nanoscale research" (Schummer, 2004: 463). Helen Lambert and Christopher McKevitt (2002) tackle the issue of applying knowledge, tools and concepts from anthropology in health care research. They point to the underdevelopment of multidisciplinarity in health care, noting that its incorporation into said research is superficial, consisting mainly in the methods borrowed from several social sciences, yet neglecting knowledge and concepts from said fields. Thus they argue that multidisciplinary research must include not just the methodologies, but also the conceptual frameworks from the fields involved. A similar point is raised by Hall and Weaver (2001) who argued that, in health care, there is a need not only for specialised health professionals, but for them to collaborate as well.

On the other hand, there is evidence that it has been used in other fields of study, especially in the realm of engineering and healthcare. Plsek and Greenhalgh (2001) maintain that in healthcare, problems and the systems that underlie them are interdependent, with less rigid boundaries, characterised by a relatively high level of dynamism and fluidity, unlike mechanical systems wherein the role and importance of each component is fixed and well defined. The growth of the body of knowledge in healthcare has led to a deeper understanding of the factors that may lead to a given conditions; for instance, an epidemic would need to be analysed from multiple perspectives: genetic factors, the environment and the lifestyle of the affected persons. The crux of their argument rests on the notion that health care needs to be understood as a complex adaptive system i.e. "a collection of individual agents with freedom to act in ways that are not always totally predictable, and whose actions are interconnected so that one agent's actions changes the context for other agents", a system that can also be described through the adaptive capabilities of its agents and their emergent behaviours. Financial markets are given as an example of such a complex adaptive system.

Another paper that focuses on the importance of multidisciplinarity in medical sciences is authored by Filler and Lipshultz (2012), who maintain that multidisciplinary clinics with a holistic approach to treatment are crucial in nephrology. Catney and Lerner (2013) argue that given the complexity of the problems that society faces today mandates a multidisciplinary approach as a viable means of enabling adequate policies to address them. On the other hand, they draw attention to the numerous challenges that a multidisciplinary research project poses, among which they cite the lack of a common basis for some of the disciplines that may be involved as well as internal resistance. Nevertheless, newer 
generations of researchers tend to take a more positive view of multidisciplinarity. Watanabe (2003) writes that there is a trend towards diversifying one's training by adding more layers to it from other discipline, invoking that there are several advantages associated with multidisciplinary training, such as: greater professional prospects; higher quality research; enriching their core training with novel perspectives; better research methodologies. Hall et al. (2017) investigated how students gauged their experience with a multidisciplinary curriculum in Geography, with results pointing towards a positive opinion of this format, citing among others increased learning opportunities, interaction with peers from various disciplines and better job market openings, with a minority of students perceiving challenges, mostly associated with "specialist knowledge and disciplinary pedagogies, social issues within the classroom and class organization and some reservations regarding groupwork".

Further on the matter of education, Peffer and Renken (2016) state that interdisciplinary, rather than multidisciplinarity research is necessary in order to allow for a more nuanced understanding of phenomena in biology as well as a more expansive education; in their view, education programmes should be able to provide students with the possibility of becoming experts in the fields they want to pursue careers in while at the same time complementing their training via interdisciplinary experiences. Like the previous authors referenced in this section, they too note challenges engendered by interdisciplinary collaborations, such as the unwillingness to acknowledge or understand other perspectives besides one's own specialisation and the possible dismissal of other points of view as lacking scientific credibility. Last but not least, James Collins (2001) advocates multidisciplinarity and interdisciplinary research as a viable academic philosophy that would allow researchers in life sciences to keep up with the dynamic pace of changes in biology.

In short, we can discern a pattern from the works cited: although in the early 2000s, the trend towards collaboration between multiple disciplines had yet to distinguish itself in the academic community, over the course of the following decade it continued to develop; nevertheless, the pace and extend to which it pervaded research and education is uneven across disciplines, with some incorporating this approach sooner in the hopes of accelerating the rate of progress, whereas others have maintained a certain adherence to a classical style of learning. While collaboration between various disciplines could yield immense professional and academic gains for researches, it does pose several challenges that vary in nature from cognitive biases and reluctance to consider viewpoints from beyond one's own specialisation, to administrative and financial issues related to funding research and managing grants.

The next section shall look into what multidisciplinarity means for economics, in light of the reaction of the public opinion and academics following the global financial crisis.

\section{Multidisciplinarity in economics}

John Maynard Keynes (1924) once famously asserted that "the master-economist must possess a rare combination of gifts...He must be mathematician, historian, statesman, philosopher - in some degree (...) no part of man's nature or his institutions must be entirely outside his regard", further positing (in reference to economist Alfred Marshall) 
that these "gifts" can be provided by mixed training. From this quote, we can infer that Keynes believed that a broader understanding of several disciplines was essential in order to be a capable economist. The relevance of this idea must be judged in light of the criticisms of economics presented earlier in this paper, in which the field, its methods and theoretical concepts are regarded as lacking grounding in real world phenomena and failing at performing what they are purported to do.

PICBE | 269

Several authors have argued in favour of a multi- and interdisciplinary approach in the study and practice of economics. For instance, Jonathan Leape (2012) makes the point that the manner in which economics is taught is insufficient, with a narrow focus, and do not grant inductive methods enough attention, preferring instead deductive reasoning flowing from theoretical assumptions while downplaying the importance of evidence and observations. Leape further makes the observation that the tendencies in economics education programmes had not shifted significantly at the time he wrote his article, despite the need for greater breadth in their education. Leape thus advocates for a wider variety in economics education to include views from other disciplines (citing among others history and anthropology) in order to gain both a deeper understanding of the phenomena that they study as well as a greater awareness of the limitations of the theoretical models used.

Soumitra Sharma (2015) offers a views along the same lines, namely that multidisciplinarity is imperative for studying the theory and practice of economics. Sharma also laments what he perceives as a stagnation of the teaching of economics; he believes that "economics must thus struggle to avoid becoming apologetics for any school of economic thought" and that economists must learn to expand their expertise towards a wider array of disciplines aside from economics, such as mathematics, philosophy, history and socio-psychology. Multidisciplinarity, in his eyes, is a solution to many ills, by cultivating the potential for innovation and progress.

Gintis (2006) argues that the economy is a complex adaptive system and should be treated as such, in contrast with standard neoclassical theory. Complexity economics is concerned with the economic as a complex system which neither lingers in a state of equilibrium nor follows a linear path, being constantly subjected to deviations and influences, and rarely can an optimum be achieved. Gintis characterises complexity economics with the help of five concepts: dynamics (nonlinearity, lacking a long-term equilibrium), agents with bounded rationality, networks created through the participation of said agents, emergence of behaviours and patterns of behaviour from the interaction of the agents, and finally evolution that is responsible for novelty and the growth of complexity. Foster's view (2004) does not disagree with Gintis's, presenting a contrast between the standard, neoclassical view that is more focused with the outcome (i.e. optimisation and equilibrium) than the economic processes, and the view of economics as a complex, adaptive system, which Foster believes should be the view that economics should head towards, following the similar trends in biology, psychology and management studies. Foster opines that the prevailing view at the time of his writing is more akin to an ideology which does not help progress.

It is worth noting that these opinions were presented only shortly before the onset of the global financial crisis. In recent years, we have seen, a trend in the direction of adding a more diversity of perspective to economics, though with varying measures of success. An 
example is econophysics, the result of applying theories, tools and methods used primarily in physics to address issues in economics. Its influence on mainstream economics has been limited, however (Ball, 2006). On the other hand, a far more successful approach has been behavioural economics, a discipline that seeks to understand economic behaviour by incorporating insights from psychology, cognitive sciences and sociology. It received particular attention following the crisis; Diacon (2014) states that the latter highlighted several flaws in the dominant neoclassical model, and through a multidisciplinary approach, behavioural economics can help lend greater clarity and accuracy to the insights yielded by economics in its analysis of human behaviour, a view supported by Agnes Virlics (2013). That behavioural economics has gained greater appreciation is also underscored by Richard Thaler winning the Nobel Memorial Prize in Economic Sciences for his contributions to this field.

Last but not least, another author who has opted for a different perspective on economic issues is MIT professor Andrew Lo (2017), who has applied insights from evolutionary biology in order to describe the economy as an adaptive system and to shed more light on the observed inconsistencies between human behavioural and theoretical predictions. In his view, economic tenets such as the efficient market hypothesis are incomplete, not altogether inaccurate, as cited by Brian Eastwood (2017). As far as academic curricula go, several major universities in Europe have begun to offer curricula in economics with a focus on multidisciplinary teaching. One such programme is provided by the London School of Economics, called the LSE100 course which is centred around tackling various social issues from the point of view of several different disciplines to refine social scientific reasoning and improve critical research (https://info.lse.ac.uk/currentstudents/lse100/about-lse-100).

Similarly, the University of Utrecht has set up a research master's programme in multidisciplinary economics based on the principle that "economics today is a multifaceted discipline with real impact on global politics, law and society" (https://www.uu.nl/masters/en/multidisciplinary-economics) and the programme aims at helping students apply a greater array of viewpoints to complex economic issues. Last but not least, the Economics department of Warwick University has stated a commitment to interdisciplinary study to offer a diverse, multilayered education to complement the core economics

programme (https://warwick.ac.uk/fac/cross_fac/iatl/cetl/fundingopps/centreprojects/graduatepledg e/researchnotes/economics/interdisciplinary/).

To synthesise this section, it appears that there is an incipient, heterogeneous pattern across the field of economics towards a multi- and interdisciplinary approach. The success and prevalence of this pattern depends largely upon the nature of the problems being studied and the goals of the research project. Apart from that, there is also the issue of overcoming the challenges that have been noted in other disciplines that have attempted the multi- and / or interdisciplinary approach, namely reluctance to new trends, frictions when interacting with other disciplines, a rigidity in maintaining the boundaries between the disciplines (which may result in disregarding other perspectives).

Last but not least, there is also the administrative issue of obtaining grants to fund multidisciplinary research in economics, which may be stimulated by the successes of 
research project. Greater diversity among faculty, complementary curricula and encouraging the efforts and insights of the younger generations of researchers are all factors that can conduce in the long term towards cementing multi- and interdisciplinarity as a core component of future economic research.

\section{A new paradigm?}

PICBE $\mid 271$

It is difficult to determine the exact moment when a paradigmatic shift occurs. When and where does one draw the line? Should it be during the years of the last global financial crisis, when neoclassical economics in general and its predictive value in particular came under heavy criticism? Should we consider it be in the year 2017, when behavioural economist Richard Thaler earned the highest distinction in the field, thus heralding a potential departure from neoclassical economics? Or rather, there is no definite moment and instead the paradigmatic shift began to happen by degrees, and may become fully fledged in the years to come?

Multidisciplinarity, as evidenced in the previous sections, comes with a lot of boons: an increased input to refine the existing analytical tools, a greater variety of methods and concepts to work with, an increased clarity which would restore the credibility of economic predictions, and greater acceptance and understanding of different economic points of view and schools. Yet, for a paradigmatic shift to occur, multidisciplinarity must first be successful, and it is through a series of academic successes that new methods, concepts and theories would emerge to gradually replace and/or refine the existing ones. Through increasingly diverse curricula, the paradigmatic shift in economic thought can find its expression in the works of the future generations, whose education would thus encourage interactions with other disciplines and help form multidisciplinary teachings, gradually adopting novel perspectives and techniques with which to address economic problems. In this sense, multi- and interdisciplinarity are visible in the horizon of economics, and a parallel may be drawn between them, on the one hand, and evolutionary algorithms, on the other, with regards to their potential to update economic theory.

As for the nature of this new paradigm, one may speculate based on the current landscape that it would be characterised by an increasing collaboration with other social sciences, especially with the increasing popularity of behavioural economics, to the extent to which economic problems would not be seen as 'purely' economic problems, for indeed the spheres of human activity (cultural, psychosocial, economic, political etc.) are entwined with one another and overlap. To quote Karl Popper (1963), "We are not students of some subject matter, but students of problems. And problems may cut right across the borders of any subject matter or discipline". Nevertheless, it is important to highlight the fact that multi- and interdisciplinarity, by their very nature, are unpredictable in the sense that it is difficult to determine beforehand what direction it will take, what cross-disciplinary links would be revealed, what disciplines economics will come in contact with and where the results thereof would lead. 


\section{Conclusions}

The objective of the paper was to analyse the concept of multidisciplinarity, settle upon a working definition of the term, analyse its potential impact on economics and discuss on whether or not it can produce a paradigmatic shift in economic thought. The paper provided a background of why a reassessment of economics is relevant in light of the criticisms that emerged against the backdrop of the last global financial crisis, where neoclassical economics and its predictive capabilities were subjected to harsh evaluations, and it was established that as the current paradigm has since been called into question, we may look into the prospects for a change in this sense.

The paper continued with the definition of multidisciplinarity, distinguishing it from other forms of cross-disciplinary collaborations such as interdisciplinarity and transdisciplinarity, settling upon a definition of multidisciplinarity as the integration of ideas, concepts, analytical tools and methodologies from various fields into the scope of one field, in order to enrich theory and gain a better, multilayered understanding of the phenomena being researched. Furthermore, we looked into multidisciplinarity in research and education in general, the picture thus created showing us that the trend is heterogeneously developed depending on each field, though in more recent years, more and more authors have signalled that, as our understanding in one field grows, so does the necessity of interacting with other disciplines to accelerate progress, but it does not come without several administrative and cognitive challenges, most noteworthy being the reluctance to interact with or acknowledge the validity of other points of view, the risk of the trend being discouraged should research projects not prove fruitful, and obtaining funds and grants.

With regards to economics, although the need for multidisciplinarity was acknowledged by John Maynard Keynes in the former half of the twentieth century, the trend was forgotten in favour of what is known as neoclassical economics which has dominated mainstream economics and which, as noted, was attacked for having failed to correctly interpret the signs that led up to the crisis after having enjoyed a long spell of popularity. Our research has revealed that in economics, incipient signs of a trend towards multidisciplinarity can be witnessed in two main forms: 1) a pattern of viewing economic problems using insights from other fields, with a preference towards behavioural economics, having experienced renewed popularity as an alternative to neoclassical economics, and 2) more diversified economic curricula created by universities with the goal of providing students with a multi- and interdisciplinary education and the chance to be exposed to other fields to complement their training as economists.

Finally, in light of the arguments presented in the paper, it has been stated that multidisciplinarity has the potential to usher in a new paradigm of economic thought, with several caveats: it is dependent upon the successes of multidisciplinary research projects to confirm its viability, and the continuity of the trend over generations. Furthermore, while current circumstances point towards greater collaboration between economics and other social sciences, the ultimate destination that this pattern will lead to is unknown due to its very nature. 


\section{References}

Andriessen, D. (2006). On the metaphorical nature of intellectual capital: a textual analysis. Journal of Intellectual Capital, 7(1), 93-110.

Aldag, R.J., \& Stearns, T.M. (1991).Management (2 ${ }^{\text {nd }}$ ed.). Cincinnati, OH: SouthWesternPublishing.

Ball, P. (2006), Econophysics: culture crash, Nature, vol. 441 (7094), pp. 686 - 688

Barnes,B.R.,Leonidou,L.C.,Siu,N.Y.M.,\&Leonidou,C.(2010).Opportunismastheinhibiting trigger for developing long-term-oriented Western exporter - Hong Kong importer relationships.JournalofInternationalMarketing, 18(2), 35-64.

Barroso, J.M.D. (2013). Speech by President Barroso on the outcome of the European Council meetingontheMultiannualFinancialFrameworkof7-

8February2013.Retrievedfrom http://europa.eu/rapid/press-release_SPEECH-13130_en.htm.

Bratianu, C. (2011a). Changing paradigm for knowledge metaphors from dynamics to thermodynamics.System Research and Behavioral Science, 28, 160-169.

Bratianu, C. (2011b). A new perspective of the intellectual capital dynamics in organizations. In Vallejo-Alonso, B., Rodriguez-Castellanos, A., Arregui-Ayastuy, G. (Eds.). Identifying, measuring, and valuing knowledge-based intangible assets: new perspectives (pp. 1-21). Hershey, PA: IGI Global.

Bratianu, C. (2013). The triple helix of the organizational knowledge.Management Dynamics in the Knowledge Economy, 1(2013), 207-220.

Ernst\&Young(2011).The sustainability revolution.Excellencein sustainability reporting awards2011.Retrieved from http://www.ey.com/ZA/en/Services/SpecialtyServices/Climate-Change- and-Sustainability-Services/2011---ESR---Main-Page.

Catney, P., Lerner, D. (2013), Managing multidisciplinarity: lessons from SUBR:IM, Interdisciplinary Science Reviews, 34(4), 290 - 308.

Choi, B.C, Pak, A.W. (2006), Multidisciplinarity, interdisciplinarity and transdisciplinarity in health education and policy: 1 . Definitions, objectives and evidence of effectiveness, Clin Invest Med, 29 (6), 351-64.

Colander, D., Follmer, H., Haas, A., Goldberg, M., Juselius, K., Kirman, A., ... \& Sloth, B. (2014). 13 The financial crisis and the systemic failure of academic economics. The Economics of Economists: Institutional Setting, Individual Incentives, and Future Prospects, 21(2-3), 344.

Collins, P. (2001), May you live in interesting times: using multidisciplinary and interdisciplinary programs to cope with change in the life sciences, BioScience, 52(1), $75-83$.

Diacon, P.E. (2014), From economic behaviour to behavioural economics, Acta Universalis Danubius OEconomica, vol. 10, no. 1, pp. 171 - 180.

Dutt, A.K. (2010), Macroeconomic theory after the crisis, paper based on a presentation made at the meetings of the American Economic Association.

Eastwood, B. (2017), Why financial markets behave like living organisms, MIT Management Sloan School Newsroom, http://mitsloan.mit.edu/newsroom/articles/why-financialmarkets-behave-like-living-organisms/.

Encyclopaedia Britannica, 5 of the world's most devastating financial crises https://www.britannica.com/list/5-of-the-worlds-most-devastating-financial-crises.

Gintis, H. (2006), The economy as a complex adaptive system, a review of Beinhocker, E. D., The origins of wealth: evolution, complexity, and the radical remaking of economics, 
http://www.umass.edu/preferen/Class\%20Material/Readings\%20in\%20Market\%20Dyna mics/Complexity\%20Economics.pdf.

Filler, G., Lipshiltz, S.E. (2012), Why multidisciplinary clinics should be the standard for treating chronic kidney disease, Pediatric Nephrology, vol. 27, issue 10, pp. 1831 1834.

Financial Times (2014), Economics needs to reflect a post-crisis world,

PICBE | 274 https://www.ft.com/content/f9f65e88-44a3-11e4-ab0c-00144feabdc0.

Foster, J. (2004), Why is economics not a complex system, Discussion Paper no. 336, School of Economics, The University of Queensland.

Goschin, Z., Zaman, Gh. (2010), Multidisciplinaritate, interdisciplinaritate şi transdisciplinaritate: abordări teoretice şi implicaţii pentru strategia dezvoltării durabile postcriză, Economie teoretică şi aplicată, XVII, 12 (553), 3 - 20.

Greenspan, A. (2013), Never saw it coming - why the financial crisis took economists by surprise, Foreign Affairs, November/December 2013 Issue, https://www.foreignaffairs.com/articles/united-states/2013-10-15/never-saw-it-coming

Hall, P., Weaver, L. (2001), Interdisciplinary education and teamwork: a long and winding road, Medical Education, vol. 35, issue 9, pp. 867 - 875.

Hall, T., McGuinness, M., Parker, C., Toms, P. (2017), Student experiences of multidisciplinarity in the undergraduate geography curriculum, Journal of Geography in Higher Education, https://doi.org/10.1080/03098265.2017.1398718.

Inman, P. (2013), Economics students aim to tear up free-market syllabus, The Guardian, https://www.theguardian.com/business/2013/oct/24/students-post-crash-economics.

Jensenius, A.R. (2012), Disciplinarities: intra, cross, multi, inter, trans, http://www.arj.no/2012/03/12/disciplinarities-2/.

Keynes, J.M. (1924), Alfred Marshall, 1842 - 1924, The Economic Journal, 34 (135), 311 372.

Lambert, H., McKevitt, C. (2002), Anthropology in health research: from qualitative methods to multidisciplinarity, BMJ, 325 (7357), $210-213$.

Leape, J. (2012), Good economists need more than economics: the multidisciplinary LSE 100 course, in Coyle, D. (ed.), What's the use of economics? Teaching the dismal science after the crisis, London: London Publishing Partnership, 183 - 192.

Le Monde (2000), Lettre ouverte des étudiants en économie, http://www.autismeeconomie.org/article2.html.

Lo, Andrew W. (2017), Adaptive markets: financial evolution at the speed of thought, Princeton: Princeton University Press.

London School of Economics, https://info.lse.ac.uk/current-students/lse100/about-lse-100.

Mearman, A., Berger, S., Guizzo, D. (2016), Curriculum reform in uk economics: a critique, Economics Working Paper Series 1611.

Mirowski, P. (2002), Machine dreams. Economics becomes a cyborg science, New York, US: Cambridge University Press.

Orrell, D. (2017), Economyths: 11 ways that economics gets it wrong, London: Icon Books.

Peffer, M., Renken, M. (2016), Practical strategies for collaboration across discipline-based education research and the learning sciences, CBE Life Sci Educ., 15(4): es11. 
Plsek, P., Greenhalgh, T. (2001), Complexity science: the challenge of complexity in health care, BMJ, 323 (7313), 625 - 628.

Popper, K. (1963), Conjectures and refutations: the growth of scientific knowledge, New York, US: Routledge.

Romer, P. (2016), The trouble with macroeconomics, http://ccl.yale.edu/sites/default/files/files/The\%20Trouble\%20with\%20Macroeconomics.

PICBE $\mid 275$ pdf.

Schummer, J. (2004), Multidisciplinarity, interdisciplinarity and patterns of research collaboration in nanoscience and nanotechnology, Scientometrics, 59(3), 425 - 465.

Sharma, S. K. (2013). Multi-disciplinarity of sciences, current economics and business. International journal of multidisciplinarity in business and scienc, 1(1), 1-5.

Stember, M. (1991), advancing the social sciences through the interdisciplinary enterprise, The Social Science Journal, 28(1), 1 - 14.

University of Utrecht, https://www.uu.nl/masters/en/multidisciplinary-economics.

Vastag, B. (2008), Assembly work, Nature, 453 (2008), 422 - 423.

Virlics, A. (2013), Emotions in economic decision making: a multidisciplinary approach, Procedia - Social and Behavioral Sciences, 92, 1011 - 1015.

Warwick University, https://warwick.ac.uk/fac/cross_fac/iatl/cetl/fundingopps /centreprojects/graduatepledge/researchnotes/economics/interdisciplinary/

Watanabe, M. (2003), Going multidisciplinary, Nature, volume 425, number 6957, 542 543.

Wharton School (2009), Why economists failed to predict the financial crisis, http://knowledge.wharton.upenn.edu/article/why-economists-failed-to-predict-thefinancial-crisis/.

Youngblood, D. (2007), Interdisciplinary studies and the bridging disciplines: a matter of process, Journal of Research Practice, 3(2), Article M18, http://jrp.icaap.org/index.php/jrp/article/view/104/101. 